\title{
Cách Trung Quốc làm khoa học và gợi ý cho Việt Nam
}

\author{
Hồ Mạnh Toàn
}

SSHPA System

Hà Nội, 18-11-2018

SSHPA (18-11-2018; Chỉnh lý, bổ sung từ bài lược dịch trên SSHPA: https://sc.sshpa.com/post/4342) - Kể từ năm 1995, đề án 211 của chính phủ Trung Quốc được phê duyệt nhằm biến 100 viện và trường đại học của nước này phù hợp hơn với thế kỉ 21. Đến năm 2015, kế hoạch Double First Class Plan (Tiếng Trung: 双一流) hỗ trợ các trường đại học hàng đầu Trung Quốc và một số khoa của các trường khác để đi đến chuẩn quốc tế.

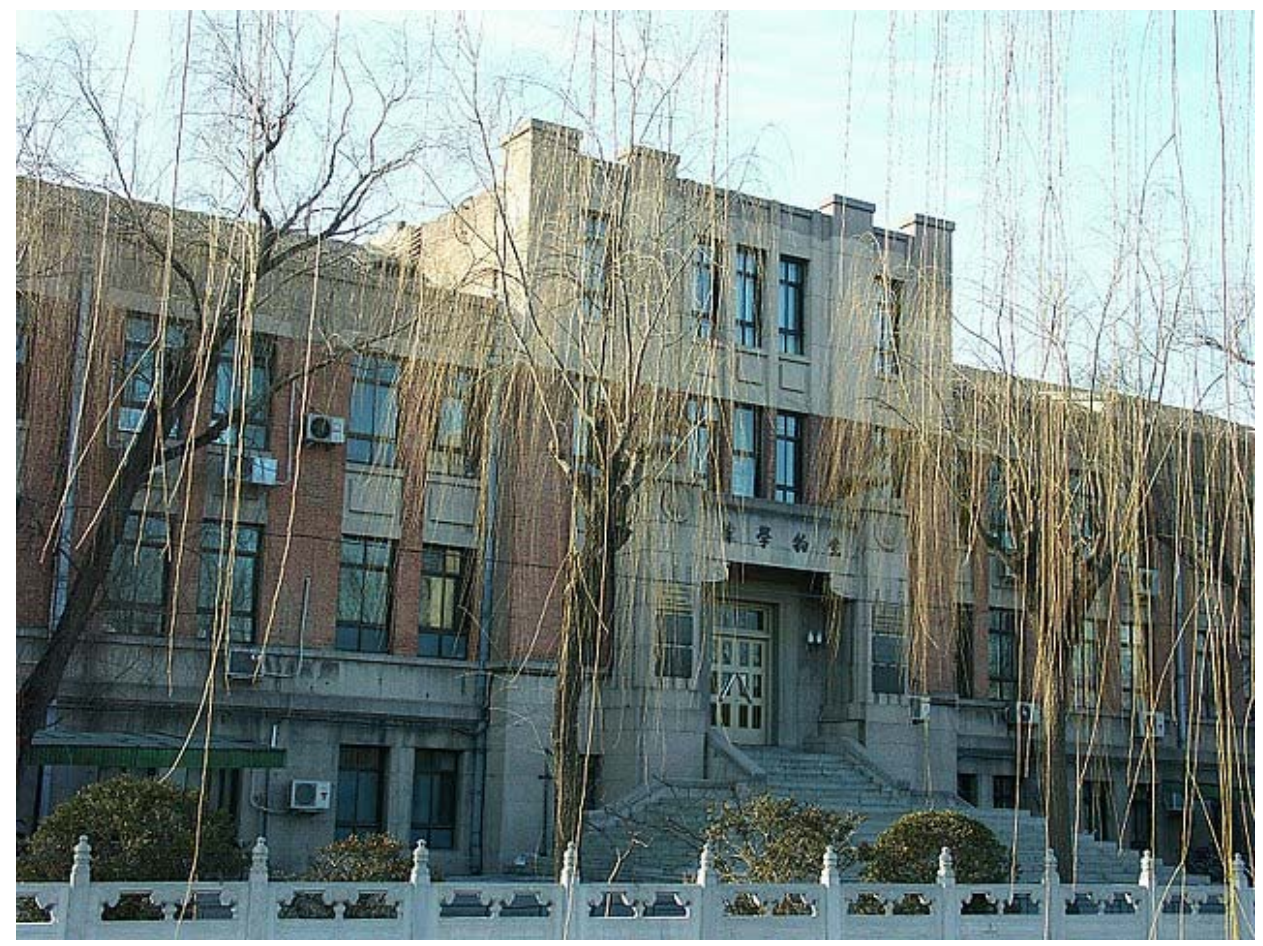

Đại học Thanh Hoa (Bắc Kinh, Trung Quốc)

Cuối cùng, cây xanh đã cho ra quả ngọt. Trong giai đoạn 2013 - 2016, trường Đại học Thanh Hoa sản xuất ra nhiều công trình thuộc top $1 \%$ trích dẫn ở ngành toán và máy tính, và top $10 \%$ trích dẫn ở khối ngành STEM nhiều hơn bất kì trường đại học nào trên 
thế giới. Cùng với Đại học Bắc Kinh, hai ngôi trường danh giá nhất Trung Quốc này có cùng mô hình như các trường đại học nghiên cứu tại Phương Tây: Thanh Hoa dẫn đầu về kĩ thuật và khoa học tự nhiên, còn Đại học Bắc Kinh là cái nôi của các nhà tư tưởng (Đại hội Triết học Thế giới 2018 được tổ chức tại đây hồi tháng 8 vừa qua).

Sự phát triển kinh tế của Trung Quốc đã thúc đẩy nền khoa học Trung Quốc thông qua các chương trình tài trợ hay tiền tưởng 'doping tài chính'. Hiện nay, mức thưởng cao nhất cho một công bố trên Nature hoặc Science cho các nhà khoa học Trung Quốc lên đến hơn 3 tỷ đồng Việt Nam. Đồng thời, kế hoạch phát triển khoa học 5 năm từ 2016 đến 2020 có ngân sách lên tới 34 tỷ USD và nhắm đến các vấn đề cơ bản của cơ bản. Tiềm lực mạnh mẽ đã trở thành bệ phóng quan trọng cho khoa học Trung Quốc.

Tuy vậy, các chiến lược phát triển của khoa học Trung Quốc, mà đại diện là Đại học Thanh Hoa được bắt đầu khi họ bắt đầu gửi các sinh viên ưu tú của mình ra nước ngoài. Hai trưởng khoa kinh tế quản trị và khoa học sự sống của Thanh Hoa đều là các ngôi sao từng kinh qua các trường lớn tại Mỹ như Columbia, Yale, Harvard, Stanford, Johns Hopkins hay Princeton. Một số điều kiện tại Thanh Hoa tuy không thể cạnh tranh được với các trường tại Mỹ nhưng với khoản lương 6 chữ số và môi trường văn hóa truyền thống cao đã giúp Thanh Hoa thu hút các nhân tài về nước.

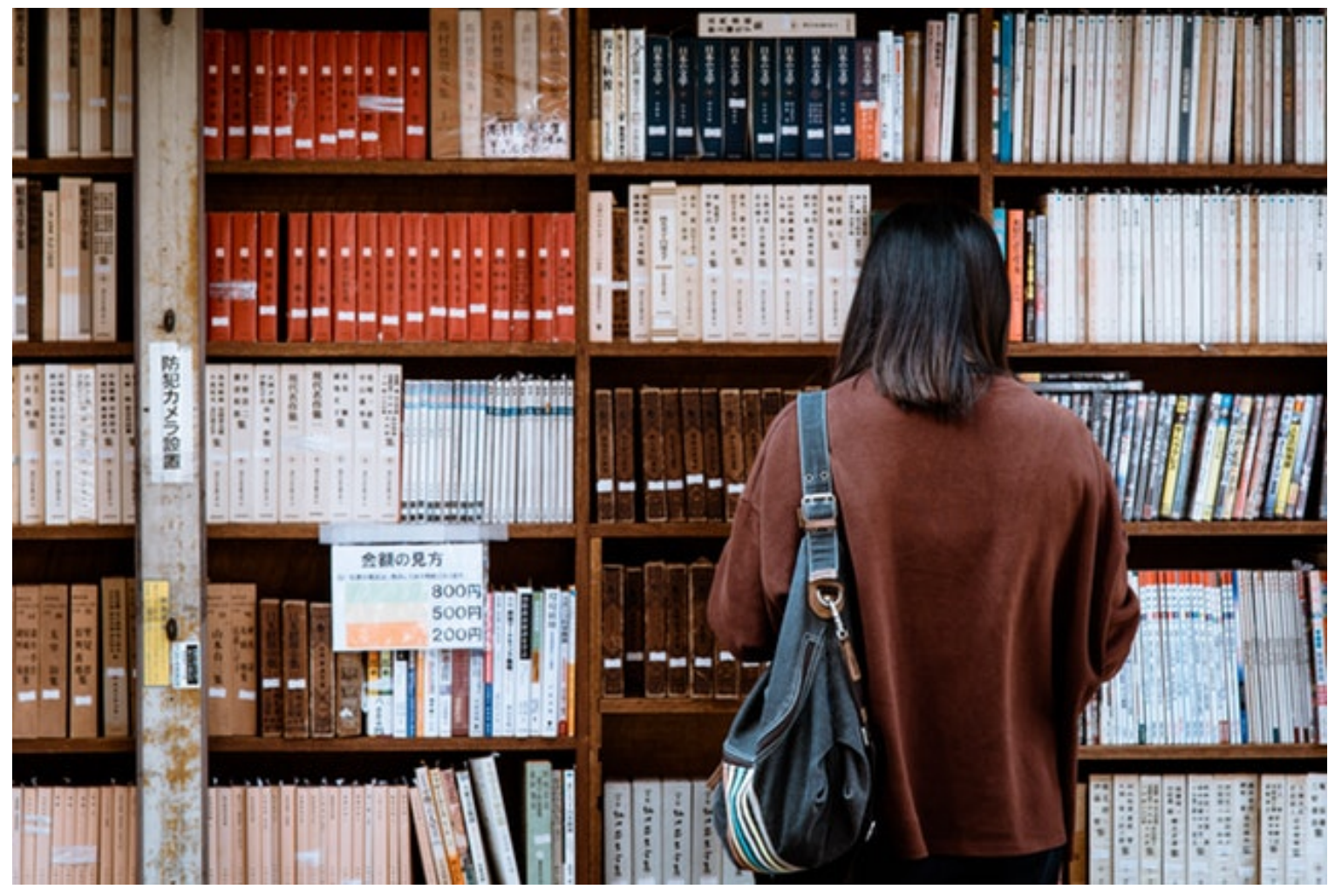

Truyền thống lịch sử và lợi ích kinh tế hấp dân 
Bên cạnh đó, cơ chế biên chế giống các trường tại Mỹ cũng là một điểm cộng để kích thích năng lực lao động của các nhà nghiên cứu. Sáu năm một lần sẽ có kiểm tra năng lực thông qua công trình đã công bố và sau đó tương lai của các nhà nghiên cứu sẽ được định đoạt. Việc nhảy vọt từ vị trí thứ 66 ở ngành toán và máy tính trong giai đoạn 2006 - 2009 lên vị trí dẫn đầu như hiện nay là kết quả của thay đổi mạnh mẽ đó.

Có thể thấy, mặc dù cùng chung gốc văn hóa đạo Khổng với Việt Nam nhưng Trung Quốc đã vượt qua được nhiều ảnh hưởng văn hóa có hại cho sự phát triển trong thời đại mới như thói quen dựa dẫm vào quan hệ hay phân hạng xã hội $[1,2]$.

Các chính sách được Thanh Hoa đưa ra để kêu gọi nhân tài như cơ chế biến chế kiểu Mỹ, lương cao nhưng lại ở trong môt trường đậm tính dân tộc là một sự hòa hợp rất hợp lí. Trong khi đó, các khoản đầu tư và thưởng lớn luôn đi kèm với những mục tiêu rất cụ thể: các nghiên cứu trên tạp chí đỉnh cao và các vấn đề cơ bản của cơ bản trong khoa học. Dù vẫn xếp sau Mỹ về kinh tế nhưng định hướng đầu tư, cũng như quan điểm làm khoa học của cho thấy sự hợp lí của một chiến lược lâu dài và nền tảng, sẽ sớm tạo ra các giá trị xã hội mạnh [3].

Hiện nay, việc đầu tư vào khoa học tại Việt nam vẫn còn gặp nhiều khó khăn do sự thiếu hợp lí và rõ ràng trong định hướng dẫn tới sự hoài nghi của người dân về khoa học và đầu tư khoa học [4]. Sự phát triển của khoa học Trung Quốc mà đại diện là Đại học Thanh Hoa [5] chính là một ví dụ cần được tham khảo kĩ càng cho các nhà hoạch định chính sách khoa học tại Việt Nam.

\section{References:}

[1] Vuong Q.H., Tran T.D. (2009). The cultural dimensions of the Vietnamese private entrepreneurship. IUP Journal of Entrepreneurship Development, VI(3-4): 54-78.

[2] Vuong Q.H., La V.P., Vuong T.T., Nguyen V.H., Ho M.T., Nguyen T.H.K., Bui Q.K., Ho M.T. (2018). Cultural additivity: Behavioural insights from the interaction of Confucianism, Buddhism, and Taoism in folktales. Palgrave Communications, 4, DOI: 10.1057/s41599-018-0189-2. URL: https:// nature.com/articles/s41599-0180189-2.

[3] United Nations Secretary-General's Scientific Advisory Board. (2015, July 9). Invest 3.5 percent GDP in science, technology, innovation for sustainable development, experts say: Experts call for advisor, not observer seat for science at leaders' policy-making table; recommends science test for pending policy decisions. Science Daily. Retrieved November 14, 2018 from www.sciencedaily.com/releases/2015/07/150709092617.htm 
[4] Vuong, Q.H. (2018). The (ir)rational consideration of the cost of science in transition economies. Nature Human Behaviour 2(1): 5 , DOI: https://doi.org/10.1038/s41562-017-0281-4. URL: https://www.nature.com/articles/s41562-017-0281-4.

[5] The Economist. (2018). Tsinghua University may soon top the world league in science research. The Economist. Retrieved from https://www.economist.com/china/ 2018/11/17/tsinghua-university-may-soon-top-the-world-league-in-scienceresearch. 